\title{
Rare lymphoid malignancies of the breast: a report of two cases illustrating potential diagnostic pitfalls
}

\author{
Evan A. Farkash • Judith A. Ferry • Nancy Lee Harris • \\ Ephraim P. Hochberg • Ronald W. Takvorian • \\ Dan S. Zuckerman • Aliyah R. Sohani
}

Received: 29 May 2009/Accepted: 3 August 2009 /Published online: 20 August 2009

(C) Springer-Verlag 2009

\begin{abstract}
Breast involvement by lymphoma is uncommon and poses challenges in diagnosis. Lymphomas may clinically, radiologically, and morphologically mimic both benign and neoplastic conditions. We describe two cases of lymphoid malignancies predominantly involving the breast, both presenting diagnostic dilemmas. The first case, ALKnegative anaplastic large-cell lymphoma involving a seroma associated with a breast implant, is an emerging clinicopathologic entity. Anaplastic large-cell lymphoma has been identified in association with breast implants and seroma formation relatively recently. The second case, hairy cell leukemia involving the breast and ipsilateral axillary sentinel lymph node, is, to our knowledge, the first reported case of hairy cell leukemia involving the breast at the time of diagnosis. While a localized bone lesion was present at time
\end{abstract}

E. A. Farkash · J. A. Ferry • N. L. Harris · A. R. Sohani James Homer Wright Pathology Laboratories,

Massachusetts General Hospital,

Boston, MA, USA

E. A. Farkash · J. A. Ferry · N. L. Harris · A. R. Sohani

Department of Pathology, Harvard Medical School,

Boston, MA, USA

E. P. Hochberg • R. W. Takvorian

Center for Lymphoma,

Massachusetts General Hospital Cancer Center,

Boston, MA, USA

D. S. Zuckerman

St. Luke's Mountain States Tumor Institute,

Boise, ID, USA

E. A. Farkash $(\bowtie)$

Department of Pathology, Massachusetts General Hospital,

55 Fruit St., WRN 219,

Boston, MA 02114, USA

e-mail: efarkash@partners.org of diagnosis, bone marrow involvement was relatively mild in comparison to that seen in the breast and lymph node. In the first case, lymphoma occurred in a clinical setting where malignancy was unsuspected, highlighting the importance of careful morphologic evaluation of paucicellular samples, as well as awareness of rare clinicopathologic entities, in avoiding a misdiagnosis of a benign inflammatory infiltrate. In the second case, the lymphoid neoplasm exhibited classic morphologic and immunophenotypic features, but presented at an unusual site of involvement. Knowledge of the patient's concurrent diagnosis of hairy cell leukemia involving the bone marrow and bone helped avoid a misdiagnosis of carcinoma rather than lymphoma.

Keywords Anaplastic large cell lymphoma - Anaplastic lymphoma kinase $\cdot$ Breast $\cdot$ Breast implant .

Hairy cell leukemia $\cdot$ Primary breast lymphoma .

Seroma $\cdot$ T-cell neoplasm

\section{Introduction}

Lymphoid malignancies are the most frequent nonepithelial neoplasms to involve the breast; however, they comprise only a small percentage of all mammary malignancies [1]. Correspondingly, the breast is an unusual site of involvement by lymphoma [2]. About half of all lymphoid malignancies involving the breast represent primary tumors; the remainder represents secondary breast involvement by a systemic neoplasm [3-5]. Most primary breast lymphomas are B-cell lymphomas; T-cell neoplasms are rare [1]. The most common lymphoma is diffuse large B-cell lymphoma followed by extranodal marginal zone lymphoma of mucosa-associated lymphoid tissue (MALT lymphoma). Less commonly seen are B-lymphoblastic lymphoma, 
Burkitt's lymphoma, peripheral T-cell lymphoma, not otherwise specified, classical Hodgkin's lymphoma, and follicular lymphoma [6, 7]. Secondary breast lymphomas show a similar distribution, with increased frequency of follicular lymphoma.

We describe two cases of rare lymphoid malignancies arising in or predominantly involving the breast. The first case of seroma-associated ALK-negative anaplastic large cell lymphoma (ALCL) occurred in a clinical setting in which malignancy was unsuspected. The second case of hairy cell leukemia exhibited the classic morphologic and immunophenotypic features of this entity, but involved a highly unusual location.

\section{Case histories}

\section{Case 1}

The patient was a 54-year-old Caucasian woman with a history of right breast carcinoma 17 years earlier, which was treated with a right mastectomy; reconstruction included bilateral silicone implants. The right silicone implant was subsequently replaced by a saline implant, and the patient remained well until 10 months before presentation, when an ultrasound performed because of gradual left breast enlargement revealed a peri-implant fluid collection. The seroma was drained, and the left silicone implant was replaced by a saline implant. At the time of implant removal and replacement, the grossly unremarkable implant capsule was examined histologically and interpreted as a chronic inflammatory infiltrate with fibrosis surrounding a pseudocystic space. Over the next 10 months, the seroma persisted despite intermittent surgical drainage.

At the time of presentation, the seroma was again aspirated, and the fluid specimen was submitted for cytological evaluation. A diagnosis of lymphoma was made, and this was followed by removal of the left saline implant and excision of the surrounding fibrous capsule. Review of the initial capsulectomy specimen from 10 months earlier revealed the presence of ALK-negative ALCL. Staging evaluation by PET-CT revealed low-level fluorodeoxyglucose (FDG) uptake within the left chest wall muscle and skin overlying the left breast, consistent with postoperative changes; no other sites of FDG avidity were identified. A bone marrow biopsy was negative for lymphoma. Ann Arbor stage was IA. The patient underwent four cycles of chemotherapy with cyclophosphamide, doxorubicin, vincristine, and prednisone (CHOP) followed by involved-field radiation therapy (45 Gy). She is in complete remission without evidence of lymphoma 7 months after diagnosis.
Case 2

The patient was a 45-year-old Caucasian woman with onset of left hip and leg pain 2 months before presentation. CBC showed mild anemia and a normal white blood cell count with an absolute monocytopenia of 175 cells $/ \mu \mathrm{L}$. She was treated initially with NSAIDs for presumed bursitis without relief then was given a 1-week prednisone taper and the pain completely resolved. A bone scan demonstrated three areas of abnormal uptake in the left proximal femur, and subsequent magnetic resonance imaging (MRI) confirmed three discrete areas within the left femur consistent with a marrow-infiltrating process. These findings were suggestive of metastatic carcinoma and prompted further radiologic evaluation. A mammogram showed an increased density in the upper outer quadrant of the left breast compared with a study 3 years earlier. CT scans of the chest, abdomen, and pelvis confirmed the left breast density and showed no splenomegaly or lymphadenopathy. Breast MRI confirmed a $2.5 \mathrm{~cm}$ left upper outer quadrant mass and also revealed a small area of enhancement in the $10 \mathrm{o}$ 'clock position of the right breast.

A stereotactic biopsy of the left breast revealed ductal carcinoma in situ (DCIS), while a subsequent core biopsy of the left proximal femur showed involvement by hairy cell leukemia. The patient then underwent a staging posterior iliac crest bone marrow biopsy and aspirate, which also showed involvement by hairy cell leukemia, and left breast lumpectomy and left axillary sentinel lymph node biopsy. The lumpectomy contained extensive DCIS, as well as prominent atypical lymphoid infiltrates with morphologic and immunohistochemical features of hairy cell leukemia. The sentinel lymph node was negative for metastatic carcinoma, but showed a massive atypical lymphoid infiltrate, consistent with nodal involvement by hairy cell leukemia. She was treated with a 7-day infusion of cladribine for hairy cell leukemia. A repeat posterior iliac crest bone marrow biopsy and aspirate performed posttreatment showed minimal residual involvement by hairy cell leukemia involving $<1 \%$ of nucleated cells.

A right breast stereotactic biopsy was then performed which revealed both invasive ductal carcinoma and DCIS. The patient underwent bilateral simple mastectomies. The left mastectomy contained residual DCIS with negative margins, as well as sparse involvement by hairy cell leukemia. The right mastectomy revealed both invasive ductal carcinoma and DCIS with negative margins and no evidence of involvement by hairy cell leukemia. A right axillary sentinel node biopsy was positive for metastatic carcinoma and negative for lymphoma. She underwent completion axillary dissection on the right and an additional 12 lymph nodes were removed, all of which were negative for carcinoma or lymphoma. After treatment with Lupron and tamoxifen, she is in complete remission from her breast 
carcinoma and hairy cell leukemia 14 months after diagnosis.

\section{Materials and methods}

Pathologic materials from both cases were submitted to our institution in consultation. These included hematoxylin and eosin (H\&E)- and immunohistochemical-stained sections of the initial capsulectomy and seroma fluid cell block, a WrightGiemsa-stained cytospin smear of the seroma fluid, and H\&Estained sections of the second capsulectomy from case 1 . Multiple materials from case 2 were sent for review including: H\&E and immunohistochemical-stained sections of the left proximal femur core biopsy, the left breast lumpectomy and axillary sentinel lymph node biopsy, and the two posterior iliac crest bone marrow biopsies; Wright-Giemsa-stained smears of the two bone marrow aspirates; reports of flow cytometric analysis performed on the bone marrow specimens; and H\&Estained sections of the left simple mastectomy.

Formalin-fixed, paraffin-embedded tissues of the second capsulectomy specimen from case 1 , and the left simple mastectomy from case 2 were available for additional immunohistochemical and in situ hybridization studies. Twomicron thick tissue sections were prepared, deparaffinized, and rehydrated according to standard laboratory protocols. A combination of ethylenediaminetetraacetic acid and boric acid in Tris buffer (CC1 reagent, Ventana) was used for antigen retrieval before primary antibody incubation. Immunohistochemistry was performed using avidin-biotin peroxidase complex with a peroxidase-labeled detection system on a Benchmark XT automated immunostainer (Ventana Medical Systems, Tucson, AZ) using validated staining protocols. In situ hybridization for kappa and lambda immunoglobulin light chains and EBV-encoded RNA (EBER) was performed using HX Automatic System Benchmark (Ventana) according to the manufacturer's instructions. Signals were detected using the Alkaline Phosphatase Enhanced Detection Kit (Ventana). Antibodies and probes studied in each case, their sources, and the dilutions used are summarized in Table 1.

In case 1, DNA was isolated from paraffin-embedded capsulectomy tissue using xylene followed by $100 \%$ ethanol rinse; deparaffinized tissue was then processed with QIAGEN QIAamp DNA micro Kits (QIAGEN, Valencia, CA). T-cell clonality assays were performed using polymerase chain reaction (PCR) according to the manufacturer's instructions with Taq polymerase (AmpliTAQ Gold, Applied Biosystems, Foster City, CA) and reagents purchased from InVivoScribe Technologies LLC, San Diego, CA (TCR $\gamma$ Gene Clonality Assay for ABI Fluorescence Detection). The kits used the primer sequences published by the BIOMED-2 [8] and products were analyzed by capillary gel electrophoresis (Applied Biosystems 3100xl, Foster City, CA).

All cytologic, histologic, immunohistochemical, and in situ hybridization studies of both cases, as well as results of molecular genetic studies in case 1 and flow cytometric
Table 1 Antibodies and probes used for immunohistochemical analysis and in situ hybridization
$H H V-8$ human herpes virus-8, EBER Epstein-Barr virus RNA

\begin{tabular}{llll}
\hline Antibody or probe & Source & Dilution & $\begin{array}{l}\text { Case(s) } \\
\text { studied }\end{array}$ \\
\hline CD3 & & & 1,2 \\
CD4 & Ventana Medical Systems, Tuscon, AZ & Prediluted & 1 \\
CD20 & Novocastra Laboratories, Newcastle Upon Tyne, UK & $1: 20$ & 1,2 \\
CD30 & Ventana Medical Systems & Prediluted & 1,2 \\
CD43 & Ventana Medical Systems & Prediluted & 1 \\
CD79a & Biogenex, CA & $1: 40$ & 1 \\
CD138 & Ventana Medical Systems & Prediluted & 1 \\
Mum1 & Serotec, Raleigh, NC & $1: 30$ & 1 \\
Pax5 & Dako Corporation, Carpinteria, CA & $1: 20$ & 1 \\
Granzyme B & Ventana Medical Systems & Prediluted & 1 \\
Perforin & Chemicon International, Chemicon, CA & $1: 10$ & 1 \\
ALK & Lab Vision Products, Freemont, CA & $1: 20$ & 1 \\
Kappa & Ventana Medical Systems & Prediluted & 1 \\
Lambda & Ventana Medical Systems & - & 1 \\
HHV-8 & Ventana Medical Systems & - & 1 \\
EBER & Advanced Biotechnologies, Columbia, MD & $1: 50$ & 1 \\
DBA.44 & INFORM EBER PROBE, Ventana Medical Systems & - & 1 \\
Cytokeratin CAM5.2 & Dako Corporation & $1: 10$ & 2 \\
Cytokeratin AE1/AE3 & Signet Laboratories, Dedham, MA & $1: 80$ & 2 \\
CD45 & Ventana Medical Systems & $1: 160$ & 2 \\
\hline
\end{tabular}


analysis in case 2 , were reviewed by four of the authors. Clinical data were obtained from medical records. The Institutional Review Board of Partners HealthCare approved this study.

\section{Results}

\section{Case 1}

Microscopic examination of the first capsulectomy specimen demonstrated dense fibrous tissue containing a few small scattered clusters of large atypical cells that were partially necrotic and inconspicuous on low-power examination (Fig. 1a and inset). The majority of the lymphoid infiltrate consisted of small lymphocytes, occasional histiocytes, and mature plasma cells. The cytospin preparation of the aspirated seroma fluid demonstrated highly atypical large cells (Fig. 1b), as did the second capsulectomy specimen. In the latter, the tumor cells were more numerous and viable with larger, multifocal aggregates than seen in the prior capsulectomy (Fig. 1c, d). Both fibrous capsules also contained refractile material consistent with silicone particles (Fig. 1e) [9]. Immunohistochemical stains of the
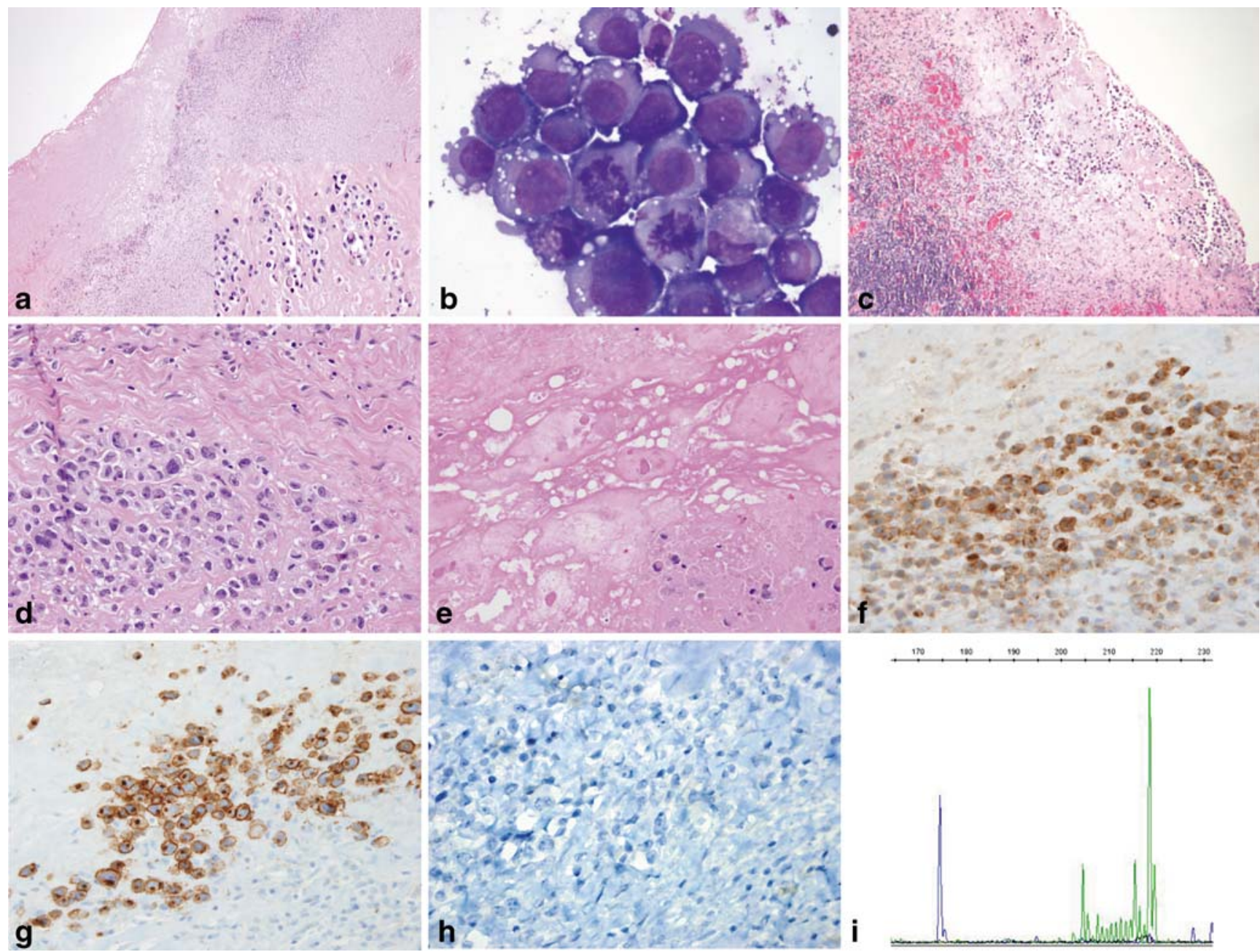

Fig. 1 ALK-negative ALCL arising in a breast peri-implant capsule and associated seroma. a Low-power examination of the initial implant capsulectomy specimen reveals an apparent benign chronic inflammatory infiltrate in a background of dense fibrosis $(\mathrm{H} \& \mathrm{E}, \times 40)$; however, atypical, but focally necrotic, large cells with hyperchromatic, irregular nuclei, and abundant eosinophilic cytoplasm are visible on high magnification (inset, H\&E, ×400). b Large malignant-appearing cells with high nuclear-to-cytoplasmic ratios, prominent nucleoli, vacuolated cytoplasm, and mitotic figures are present in a cytospin of the seroma aspirate (Wright-Giemsa stain, $\times 1,000)$. c The second implant capsulectomy contains fibrosis, chronic inflammation, and more conspicuous clusters of large, atypical cells adjacent to the seroma cavity $(H \& E, \times 100)$. d Viable clusters of large infiltrating cells have pleomorphic nuclei and prominent nucleoli with occasional "hallmark cells" present $(H \& E, \times 400)$. e The implant capsule contains focal deposits of refringent, nonpolarizable material consistent with silicone adjacent to partially viable clusters of large atypical cells $(\mathrm{H} \& \mathrm{E}, \times 400)$. f-h Immunohistochemical staining demonstrates the neoplastic cells to be positive for CD4 (f) and CD30 (g), but negative for ALK-1 $(\mathbf{h} ; \times 400)$. i T-cell receptor PCR identified a clonal rearrangement with $\mathrm{V} \gamma 10$ primers $(174.5 \mathrm{bp}$, blue tracing), as well as an indeterminate peak with $\mathrm{V} \gamma 1-8$ primers (218.6 bp, green tracing), consistent with the presence of a clonal Tcell population 
first capsulectomy and cell block specimens demonstrated the large cells to be positive for CD30, CD4, and CD43, and negative for ALK-1, CD2, CD3, CD5, CD7, CD8, CD15, CD45, and cytokeratins AE1/AE3 and CAM5.2 (Fig. 1f-h). Additional immunohistochemical and in situ hybridization studies performed on the second capsulectomy specimen showed the tumor cells to be strongly positive for Mum-1, and negative for CD20, CD79a, Pax5, CD138, kappa and lambda immunoglobulin light chains, HHV-8, and EBER. PCR demonstrated the presence of a clonal rearrangement of the T-cell receptor gene with $\mathrm{V} \gamma 10$ primers, as well as a peak of indeterminate relative height with V $\gamma 1-8$ primers (Fig. 1i). Based on these morphologic, immunohistochemical, and molecular genetic findings, a diagnosis of ALK-negative ALCL was made on all three specimens.

\section{Case 2}

Microscopic examination of the left femur core biopsy revealed replacement of bone by a dense infiltrate of small lymphoid cells with abundant pale cytoplasm. The posterior iliac crest bone marrow biopsy showed a normocellular marrow with trilineage hematopoiesis with an atypical infiltrate of small to medium-sized lymphoid cells in a patchy, interstitial distribution, comprising approximately $30 \%$ of the overall cellularity (Fig. 2a). The cells had oval to spindle-shaped nuclei with dispersed chromatin and abundant pale cytoplasm. On examination of the aspirate smear, numerous characteristic hairy cells were identified (Fig. 2a inset). Immunohistochemical stains of both the femur and bone marrow specimens showed the lymphoid cells to be positive for CD45, CD20, and DBA.44 and negative for CD3 and cytokeratin AE1/AE3 (Fig. 2a). Flow cytometry identified an abnormal lymphoid population comprising $6 \%$ of all cells with increased light scatter and expression of CD19, CD20, CD22, FMC-7, CD11c, CD25 (partial), CD103, and monotypic lambda immunoglobulin light chain. The cells were negative for CD5, CD10, and CD23. The morphologic and immunophenotypic findings were diagnostic of hairy cell leukemia involving the bone marrow and proximal femur.

Gross examination of the left breast lumpectomy revealed two well-circumscribed, tan-white nodules measuring 1.7 and $0.7 \mathrm{~cm}$. On microscopic examination, the nodules corresponded to dense stromal infiltrates of monotonous small cells; extensive cribriform DCIS was also present in these and adjacent areas (Fig. 2b-d). In areas of low cellularity, the small cells were difficult to identify, and had a cytomorphology and linear infiltrative pattern reminiscent of the classic type of invasive lobular carcinoma [10]. In more cellular areas where the tumor cells formed larger aggregates and sheets, the infiltrate resem- bled the less common alveolar or solid types of invasive lobular carcinoma $[10,11]$. The left axillary sentinel node was almost entirely replaced by sheets of similar-appearing cells (Fig. 2e and inset). Immunohistochemical stains revealed the atypical cells within the breast stroma and lymph node to be positive for CD20 and DBA.44 and negative for $\mathrm{CD} 3$ and cytokeratin AE1/AE3 (Fig. 2f). Based on the morphologic and immunophenotypic findings, and the presence of synchronous disease in the bone and bone marrow, a diagnosis of hairy cell leukemia involving the left breast and axillary sentinel lymph node was made.

The posterior iliac crest bone marrow biopsy performed after treatment with cladribine revealed a normocellular marrow with maturing trilineage hematopoiesis; no atypical lymphoid infiltrate was seen morphologically. However, flow cytometric analysis revealed a small abnormal population comprising $<1 \%$ of all cells with expression of CD19, CD20 (bright), CD11c, CD25, CD103, and monotypic lambda immunoglobulin light chain. The findings were consistent with minimal residual bone marrow involvement by hairy cell leukemia. The left simple mastectomy showed foci of residual DCIS involving a healing biopsy site. Also present in between both benign and malignant ducts and lobules was a sparse infiltrate of cells with oval nuclei and abundant pale cytoplasm (Fig. 2g). Immunohistochemical stains showed these cells to be positive for CD45, CD20, and DBA.44 and negative for $\mathrm{CD} 3$ and cytokeratins AE1/AE3 and CAM5.2, consistent with residual hairy cell leukemia (Fig. 2h, i). The degree of breast involvement was markedly decreased compared with the pretreatment lumpectomy specimen.

\section{Discussion}

Both cases of lymphoma involving the breast described here represent rare lymphoma subtypes, and hence presented diagnostic challenges. The case of ALK-negative ALCL occurred in a clinical setting in which malignancy was not suspected, and the malignant cells were initially overlooked. ALCL is characterized by the presence of large cells with abundant cytoplasm and pleomorphic, often horseshoe-shaped nuclei, termed "hallmark cells", with expression of CD30, and often loss of multiple pan-T-cell antigens. The presence of the anaplastic lymphoma kinase $(A L K)$ gene translocation and expression of ALK protein defines ALK-positive ALCL, which occurs in children and young adults and has a relatively favorable prognosis, while ALK-negative ALCL occurs in older individuals who often present with advanced disease and has a worse outcome, although better than that for peripheral T-cell lymphoma, not otherwise specified [12-14]. ALK-negative ALCL 

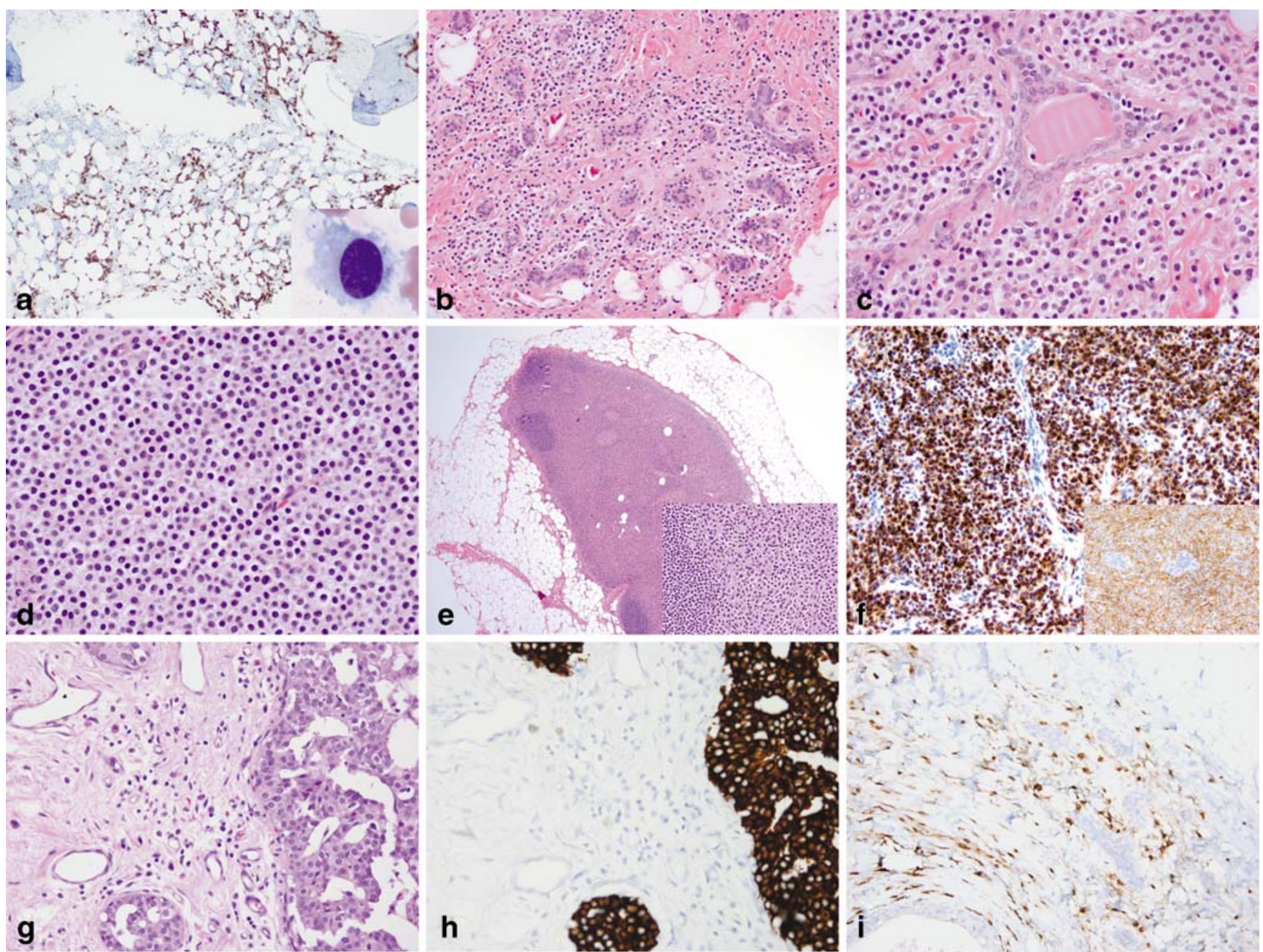

Fig. 2 Hairy cell leukemia involving the bone marrow, breast, and axillary sentinel lymph node. a A posterior iliac crest bone marrow aspirate smear contains medium-sized lymphoid cells with oval nuclei, dispersed chromatin, and abundant pale cytoplasm with circumferential cytoplasmic projections (inset, Wright-Giemsa, $\times 1,000$ ). CD20 stain of the core biopsy highlights the interstitial pattern of marrow involvement characteristic of hairy cell leukemia $(\times 100)$. b-d Left breast lumpectomy containing prominent monomorphic infiltrates of small discohesive cells with abundant pale cytoplasm and round to oval nuclei present singly and in linear strands surrounding benign lobules $(\mathbf{b} ; \mathrm{H} \& \mathrm{E}, \times 200)$, as larger clusters and aggregates surrounded by thin bands of fibrous stroma (c; H\&E, $\times 400)$, as well as in solid sheets (d; H\&E, ×400). DCIS was present elsewhere (not shown). e The sentinel lymph node shows massive replacement of the paracortex and hilum by cells with abundant pale eosinophilic cytoplasm and oval to spindled nuclei, morphologically similar to those in the breast (inset, $\mathrm{H} \& \mathrm{E}, \times 400$ ); residual primary follicles are present at the periphery of the node $(H \& E, \times 20)$. f Immunohistochemistry of the breast specimen reveals infiltrating cells to be CD20positive (inset) and strongly DBA.44-positive $(\times 400)$. g Subsequent mastectomy demonstrates an infiltrate of monomorphic cells present singly and in loose linear arrays adjacent to residual cribriform DCIS (H\&E, ×400). h-i A cytokeratin cocktail immunostain (h) of the mastectomy specimen highlights DCIS, but not the infiltrating cells, which are positive for $\mathrm{CD} 20(\mathbf{i} ; \times 400)$

ulceration [16-22]. ALK-negative ALCL has been identified after both cosmetic augmentation and reconstruction following mastectomy for primary breast carcinomas. Most affected patients have had a good prognosis with prolonged disease-free survival despite negativity for ALK, leading some investigators to suggest that this clinicopathologic entity may be more closely related to the primary cutaneous form of ALCL [17]. Indeed, prognosis in nonnodal ALCL may be more closely related to site of presentation than to ALK status [23]. 
Although breast implants do not appear to increase the risk of subsequent development of breast carcinoma [24], there may be an etiologic association between prolonged exposure to silicone from breast implants and the rare development of ALK-negative ALCL [16-18, 25]. There is speculation that exposure to silicone, due to microscopic leaks from silicone-filled implants or from saline-filled implants containing silicone-impregnated capsules, drives an immunologic reaction that leads to T-cell activation, clonal expansion, and the eventual development of lymphoma $[16-18,26]$.

The diagnosis in this case was challenging for several reasons. At the time of the first silicone implant removal and replacement, malignancy was not suspected. Not only was the patient in complete remission from her breast cancer, but there existed at that time only isolated case reports in the literature of the association between ALKnegative ALCL, breast implant capsules, and seroma formation [18, 19, 21, 22], so there was little awareness of this diagnostic entity. On morphological examination, the initial capsulectomy specimen was sparsely cellular, with only rare partially degenerated atypical cells. The diagnosis of ALK-negative ALCL was rendered on an aspirate of the seroma fluid that was sent for cytologic evaluation in which cellular detail was well-preserved, leading to the identification of frankly malignant nuclear features and review of the previous specimen. The second capsulectomy specimen showed more extensive involvement by lymphoma with greater tumor cell viability and more conspicuous "hallmark cells". This case highlights the importance of careful morphologic evaluation of paucicellular or degenerated samples, even in instances where the clinical suspicion for malignancy is low. It also illustrates the importance of maintaining an awareness of emerging diagnostic entities associated with specific clinical and pathological settings, even those that occur with low frequency.

The case of hairy cell leukemia exhibited classic morphologic and immunophenotypic features of this entity [27], but the diagnosis was challenging because of the unusual clinical presentation in the breast. The clinical symptom of leg pain, in combination with the radiological findings of masses in both the breasts and femur, was more suggestive of metastatic breast carcinoma than a hematologic malignancy. The initial core biopsy of the breast showing DCIS reinforced this clinical suspicion. In this context, the morphological differential diagnosis of a breast tumor composed of small discohesive cells with abundant cytoplasm included invasive lobular carcinoma [10, 11]. The relatively small nuclear size and minimal cytological atypia were subtle clues to the lymphoid, rather than epithelial, nature of the cells. Importantly, knowledge of the patient's concurrent diagnosis of hairy cell leukemia involving the femur and bone marrow led to the performance of an appropriate panel of immunohistochemical stains and confirmation of the diagnosis.

Hairy cell leukemia typically involves bone marrow and spleen but may also involve other sites including the central nervous system, gastrointestinal and urogenital tracts, heart, lungs, skeletal muscle, skin, thymus, and thyroid [28-32]. Breast involvement, either at the time of diagnosis or later in the disease course, has not been reported to our knowledge. Since breast tissue is rarely sampled at the time of autopsy, the breast may be an under-recognized site of involvement in established disease. Lymph node and skeletal involvement have been reported in hairy cell leukemia and typically occur at an advanced stage of disease $[27,33]$. Therefore, a striking feature in this case is the prominent degree of breast and axillary sentinel lymph node involvement and involvement of a localized bone lesion at the time of diagnosis, in the absence of extensive bone marrow involvement or splenomegaly.

In summary, we report two unusual cases of lymphoma involving the breast that presented diagnostic challenges. In the case of seroma-associated ALK-negative ALCL, the presence of malignancy was unsuspected clinically and was initially overlooked, but the clinical findings of a longstanding breast implant complicated by recurrent periimplant seroma formation fit the clinical profile of an emerging diagnostic entity, and repeat cytologic evaluation with an appropriate panel of immunohistochemical stains led to the correct diagnosis. In the case of hairy cell leukemia, the patient presented with clinical findings suggestive of metastatic carcinoma rather than lymphoma. Careful attention to the concomitant diagnosis of hairy cell leukemia involving other sites helped to avoid a misdiagnosis of invasive carcinoma. Both cases illustrate the importance of performing a careful and thorough clinical and pathological evaluation when considering a diagnosis of a rare lymphoma subtype involving the breast.

Acknowledgements The authors are grateful to Ms. Michelle Lee for her assistance with the illustrations.

\section{References}

1. Lamovec J, Wotherspoon A, Jacquemier J (2003) Malignant lymphoma and metastatic tumours. In: Tavassoli F, Devilee P (eds) Tumors of the breast and female genital organs. World Health Organization classification of tumours. IARC, Lyon, pp 107-109

2. Brogi E, Harris NL (1999) Lymphomas of the breast: pathology and clinical behavior. Semin Oncol 26:357-364

3. Talwalkar SS, Miranda RN, Valbuena JR, Routbort MJ, Martin AW, Medeiros LJ (2008) Lymphomas involving the breast: a study of 106 cases comparing localized and disseminated neoplasms. Am J Surg Pathol 32:1299-1309 
4. Kuper-Hommel MJ, Snijder S, Janssen-Heijnen ML et al (2003) Treatment and survival of 38 female breast lymphomas: a population-based study with clinical and pathological reviews. Ann Hematol 82:397-404

5. Wiseman C, Liao KT (1972) Primary lymphoma of the breast. Cancer 29:1705-1712

6. Gholam D, Bibeau F, El Weshi A, Bosq J, Ribrag V (2003) Primary breast lymphoma. Leuk Lymphoma 44:1173-1178

7. Wood NL, Coltman CA (1973) Localized primary extranodal Hodgkin's disease. Ann Intern Med 78:113-118

8. van Dongen JJ, Langerak AW, Bruggemann M et al (2003) Design and standardization of PCR primers and protocols for detection of clonal immunoglobulin and T-cell receptor gene recombinations in suspect lymphoproliferations: report of the BIOMED-2 Concerted Action BMH4-CT98-3936. Leukemia 17:2257-2317

9. Bleiweiss IJ, Klein MJ, Copeland M (1996) Breast prosthesis reaction. Am J Surg Pathol 20:505-507

10. du Toit RS, Locker AP, Ellis IO, Elston CW, Nicholson RI, Blamey RW (1989) Invasive lobular carcinomas of the breastthe prognosis of histopathological subtypes. Br J Cancer 60:605609

11. Orvieto E, Maiorano E, Bottiglieri L et al (2008) Clinicopathologic characteristics of invasive lobular carcinoma of the breast: results of an analysis of 530 cases from a single institution. Cancer 113:1511-1520

12. Delsol G, Falini B, Muller-Hermelink HK et al (2008) Anaplastic large cell lymphoma, ALK-positive. In: Swerdlow SH, Campo E, Harris NL et al (eds) WHO classification of tumours of haematopoietic and lymphoid tissues, 4th edn. IARC Press, Lyon, pp 312-316

13. Mason DY, Harris NL, Delsol G et al (2008) Anaplastic large cell lymphoma, ALK-negative. In: Swerdlow SH, Campo E, Harris NL et al (eds) WHO classification of tumours of haematopoietic and lymphoid tissues, 4th edn. IARC Press, Lyon, pp 317-319

14. Savage KJ, Harris NL, Vose JM et al (2008) ALK- anaplastic large-cell lymphoma is clinically and immunophenotypically different from both ALK+ ALCL and peripheral T-cell lymphoma, not otherwise specified: report from the International Peripheral TCell Lymphoma Project. Blood 111:5496-5504

15. Ralfkiaer E, Willemze R, Paulli M, Kadin ME (2008) Primary cutaneous CD30-positive T-cell lymphoproliferative disorders. In: Swerdlow SH, Campo E, Harris NL et al (eds) WHO classification of tumours of haematopoietic and lymphoid tissues, 4th edn. IARC Press, Lyon, pp 320-321

16. Wong AK, Lopategui J, Clancy S, Kulber D, Bose S (2008) Anaplastic large cell lymphoma associated with a breast implant capsule: a case report and review of the literature. Am J Surg Pathol 32:1265-1268

17. Roden AC, Macon WR, Keeney GL, Myers JL, Feldman AL, Dogan A (2008) Seroma-associated primary anaplastic large-cell lymphoma adjacent to breast implants: an indolent T-cell lymphoproliferative disorder. Mod Pathol 21:455-463

18. Fritzsche FR, Pahl S, Petersen I, Burkhardt M, Dankof A, Dietel M, Kristiansen G (2006) Anaplastic large-cell non-Hodgkin's lymphoma of the breast in periprosthetic localisation 32 years after treatment for primary breast cancer - a case report. Virchows Arch 449:561-564

19. Olack B, Gupta R, Brooks GS (2007) Anaplastic large cell lymphoma arising in a saline breast implant capsule after tissue expander breast reconstruction. Ann Plast Surg 59:56-57

20. Keech JA Jr, Creech BJ (1997) Anaplastic T-cell lymphoma in proximity to a saline-filled breast implant. Plast Reconstr Surg 100:554-555

21. Sahoo S, Rosen PP, Feddersen RM, Viswanatha DS, Clark DA, Chadburn A (2003) Anaplastic large cell lymphoma arising in a silicone breast implant capsule: a case report and review of the literature. Arch Pathol Lab Med 127:e115-e118

22. Gaudet G, Friedberg JW, Weng A, Pinkus GS, Freedman AS (2002) Breast lymphoma associated with breast implants: two case-reports and a review of the literature. Leuk Lymphoma 43:115-119

23. ten Berge RL, Oudejans JJ, Ossenkoppele GJ et al (2000) ALK expression in extranodal anaplastic large cell lymphoma favours systemic disease with (primary) nodal involvement and a good prognosis and occurs before dissemination. J Clin Pathol 53:445-450

24. Brinton LA, Lubin JH, Burich MC, Colton T, Brown SL, Hoover RN (2000) Breast cancer following augmentation mammoplasty (United States). Cancer Causes Control 11:819-827

25. de Jong D, Vasmel WL, de Boer JP, Verhave G, Barbe E, Casparie MK, van Leeuwen FE (2008) Anaplastic large-cell lymphoma in women with breast implants. JAMA 300:2030-2035

26. Copeland M, Choi M, Bleiweiss IJ (1994) Silicone breakdown and capsular synovial metaplasia in textured-wall saline breast prostheses. Plast Reconstr Surg 94:628-636

27. Foucar K, Falini B, Catovsky D, Stein H (2008) Hairy cell leukaemia. In: Swerdlow SH, Campo E, Harris NL et al (eds) WHO classification of tumours of haematopoietic and lymphoid tissues, 4th edn. IARC Press, Lyon, pp 188-190

28. Burke JS, Byrne GE Jr, Rappaport H (1974) Hairy cell leukemia (leukemic reticuloendotheliosis). I. A clinical pathologic study of 21 patients. Cancer 33:1399-1410

29. Vardiman JW, Golomb HM (1984) Autopsy findings in hairy cell leukemia. Semin Oncol 11:370-380

30. Vardiman JW, Variakojis D, Golomb HM (1979) Hairy cell leukemia: an autopsy study. Cancer 43:1339-1349

31. Hoffman MA (2006) Clinical presentations and complications of hairy cell leukemia. Hematol Oncol Clin North Am 20:1065-1073

32. Dedic K (2003) Hairy cell leukemia: an autopsy study. Acta Medica (Hradec Kralove) 46:175-177

33. Lembersky BC, Ratain MJ, Golomb HM (1988) Skeletal complications in hairy cell leukemia: diagnosis and therapy. $\mathrm{J}$ Clin Oncol 6:1280-1284 